\title{
BMJ Global Health What the percentage of births in facilities does not measure: readiness for emergency obstetric care and referral in Senegal
}

Francesca L Cavallaro (D) , ,2 Lenka Benova, ${ }^{3,4}$ El Hadji Dioukhane, ${ }^{5}$ Kerry Wong (D) , ${ }^{4}$ Paula Sheppard, ${ }^{6}$ Adama Faye, ${ }^{7}$ Emma Radovich (D) , ${ }^{4}$ Alexandre Dumont, ${ }^{1}$ Abdou Salam Mbengue, ${ }^{8}$ Carine Ronsmans, ${ }^{4}$ Melisa Martinez-Alvarez ${ }^{9}$

To cite: Cavallaro FL, Benova L, Dioukhane EH, et al. What the percentage of births in facilities does not measure: readiness for emergency obstetric care and referral in Senegal. BMJ Global Health 2020;5:e001915. doi:10.1136/ bmjgh-2019-001915

Handling editor Seye Abimbola

- Additional material is published online only. To view please visit the journal online (http://dx.doi.org/10.1136/ bmjgh-2019-001915).

Received 14 August 2019 Revised 20 January 2020 Accepted 27 January 2020

Check for updates

C Author(s) (or their employer(s)) 2020. Re-use permitted under CC BY-NC. No commercial re-use. See rights and permissions. Published by BMJ.

For numbered affiliations see end of article.

Correspondence to Dr Francesca L Cavallaro; f.cavallaro@ucl.ac.uk

\section{ABSTRACT}

Introduction Increases in facility deliveries in subSaharan Africa have not yielded expected declines in maternal mortality, raising concerns about the quality of care provided in facilities. The readiness of facilities at different health system levels to provide both emergency obstetric and newborn care (EmONC) as well as referral is unknown. We describe this combined readiness by facility level and region in Senegal.

Methods For this cross-sectional study, we used data from nine Demographic and Health Surveys between 1992 and 2017 in Senegal to describe trends in location of births over time. We used data from the 2017 Service Provision Assessment to describe EmONC and emergency referral readiness across facility levels in the public system, where $94 \%$ of facility births occur. A national global positioning system facility census was used to map access from lowerlevel facilities to the nearest facility performing caesareans. Results Births in facilities increased from $47 \%$ in 1992 to $80 \%$ in 2016, driven by births in lower-level health posts, where half of facility births now occur. Caesarean rates in rural areas more than doubled but only to $3.7 \%$, indicating minor improvements in EmONC access. Only 9\% of health posts had full readiness for basic EmONC, and $62 \%$ had adequate referral readiness (vehicle on-site or telephone and vehicle access elsewhere). Although public facilities accounted for three-quarters of all births in 2016, only $16 \%$ of such births occurred in facilities able to provide adequate combined readiness for EmONC and referral. Conclusions Our findings imply that many lower-level public facilities-the most common place of birth in Senegal-are unable to treat or refer women with obstetric complications, especially in rural areas. In light of rising lower-level facility births in Senegal and elsewhere, improvements in EmONC and referral readiness are urgently needed to accelerate reductions in maternal and perinatal mortality.

\section{INTRODUCTION}

In recent decades, maternal mortality has decreased in sub-Saharan Africa; however, progress was insufficient to meet Millennium

\section{Key questions}

What is already known?

- Despite increases in facility deliveries in sub-Saharan Africa, maternal and perinatal mortality remains unacceptably high, partly due to limited readiness to treat obstetric complications in facilities.

What are the new findings?

- In Senegal, although three-quarters of births occurred in public facilities in 2016 , only $16 \%$ of these took place in facilities able to provide comprehensive emergency obstetric and newborn care (EmONC), or basic EmONC and referral to a comprehensive EmONC facility.

- $37 \%$ of rural health posts were located more than 1-hour drive from the nearest facility performing caesareans.

\section{What do the new findings imply?}

- Lower-level public health posts-the most common place of birth in Senegal-are often unable to provide high-quality care during childbirth, or timely emergency referral to a higher-level facility.

- Improvements in referral and EmONC readiness, particularly in rural areas, are urgently needed in lower-level facilities in Senegal and other countries where many births occur in lower-level facilities.

- Measuring facilities' capacity to provide EmoNC or refer to such facilities within a reasonable travel time is a powerful means of identifying women and areas that are left behind.

Development Goal 5 in most countries. ${ }^{1}$ The global maternal health community must now focus on countries left behind and accelerate progress to achieve Sustainable Development Goals (SDGs) target 3.1 for maternal health. Sub-Saharan Africa has the highest burden of maternal and perinatal mortality. ${ }^{2-4}$ Limited improvements in maternal and perinatal 
outcomes despite rising facility deliveries raises questions regarding the quality of care provided in health facilities. $^{5-7}$

Skilled attendance at birth and access to emergency obstetric and newborn care (EmONC) are essential for preventing maternal and perinatal deaths. ${ }^{89}$ There is agreement that a strategy of universal facility deliveries with a skilled birth attendant (SBA) is optimal for reducing mortality. ${ }^{10}$ Accordingly, the percentage of births in facilities and with SBA are commonly used to track coverage of maternal care services. ${ }^{11}$ However, there is great variability in the quality of care offered across facilities and birth attendants. In the 2016 Lancet Maternal Health series, Campbell et al proposed a framework outlining safe care pathways for women and their babies, arguing most deliveries should occur in facilities providing at least basic EmONC (BEmONC), as well as either comprehensive EmONC (CEmONC) or facilitated referral to a CEmONC facility. ${ }^{9}$ The recent Lancet Quality Care Commission argued that redesigning services to shift delivery care from lower-level facilities to health centres or hospitals could yield significant gains in quality of maternal and neonatal care, without unduly compromising geographical access to care. ${ }^{12}$

Previous studies have highlighted low readiness to provide childbirth care in health facilities in sub-Saharan Africa, due to low provider skill and suboptimal equipment and supplies. ${ }^{13-21}$ Evidence on referral systems for transferring patients with complications between facilities in low-income countries is limited ${ }^{22}$ but indicates that these are often not functional or non-existent, with lack of communication and transport means, and poor road infrastructure. ${ }^{23-25}$ Overall, there is little evidence on readiness for EmONC jointly with referral capacity, despite referral being necessary for safe childbirth care in non-CEmONC facilities, and on readiness by facility level or geographical area.

This paper addresses these gaps in the evidence base by mapping Campbell's framework against the health systems framework used by governments to organise maternal and newborn health services and allocate resources. In an attempt to bring childbirth services closer to women and increase facility deliveries, several governments in sub-Saharan Africa have encouraged births in lower-level dispensaries or health posts; however, this strategy risks offering substandard care far away from any referral hospital. ${ }^{12}$ Among these countries, Senegal has achieved $80 \%$ facility births, but a large proportion of these are attended by unskilled attendants. ${ }^{9}$ It also has recent women and facility surveys available. We therefore selected Senegal as a case study to investigate the potential quality of care implications of these national policies, which need to be aligned with international EmONC frameworks. We propose an approach to assess readiness for EmONC and emergency referral within countries by examining facilities at different levels of the health system (hospitals, health centres, health posts and health huts), as well as across urban/rural areas and geographical regions, to identify gaps in care provision and facilitate the prioritisation of resource allocation. This study provides evidence that will inform policy-makers' strategies in Senegal and other low-income and middle-income countries to accelerate reductions in maternal mortality. In addition, it aims to stimulate global debate on indicators used to assess maternal health system readiness and use, and their role in shaping strategies to reduce maternal mortality.

\section{METHODS \\ Conceptual framework}

This paper addresses two central research questions: first, where do women deliver in Senegal and how has this changed over time? Second, what is the readiness for treating obstetric complications and referring women with complications, according to facility level and region? We used Campbell et al's conceptual framework of pathways to adequate childbirth care ${ }^{9}$ to systematically assess service readiness in hospitals, health centres, health posts and health huts. Within this framework, deliveries should occur either in a CEmONC facility, or a BEmONC facility with facilitated emergency referral to a CEmONC facility, in case the woman develops complications-we consider facilities in these categories to provide minimum safe conditions for childbirth. We assessed facilities' readiness for EmONC and emergency referral jointly among public facilities included in the Service Provision Assessment (SPA), and calculated driving time from facilities without caesarean capacity to those with caesarean capacity among all public facilities in Senegal. We did not calculate driving times from BEmONC to CEmONC facilities as proposed by Ebener et $a l^{26}$ because it was not possible to ascertain EmONC readiness for all health facilities in Senegal, and most facilities did not fall into either BEmONC or CEmONC categories.

\section{Setting}

Senegal is a West African country (population of 16 million in 2017) with large rural areas and long distances to health facilities, limiting access to childbirth care. ${ }^{27}$ Large regional disparities exist in healthcare infrastructure, utilisation and outcomes, with more urbanised coastal regions in the West-including the capital Dakar-performing better than predominantly rural regions in the East and South (box 1). ${ }^{28} 29$

Senegal's public health system is pyramid shaped, with health posts referring patients to their district health centre, and health centres referring patients to the regional hospital. ${ }^{30}$ Some health posts further coordinate a small network of rural health huts. Regional and national hospitals are intended to provide all CEmONC signal functions, including caesarean sections, while few health centres have surgical capacity. Health posts are lower-level facilities with a small number of inpatient beds, traditionally staffed by nurses and matrones (birth assistants with 3-6 months of training, considered 
Box 1 Sociodemographic characteristics of regions in Senegal

- Urban centre: The capital Dakar is the most urbanised region of Senegal, with $97 \%$ urban population. It contains approximately onequarter of the country's population, and has the highest population density with more than 6000 inhabitants per $\mathrm{km}^{2}$ as well as the lowest total fertility rate at 3.0 children per woman. Only $5 \%$ of women report distance to health facilities as a barrier to accessing healthcare.

- Rural regions with large urban centres: Four regions (Thiès, Kaolack, Saint-Louis and Ziguinchor) have large urban centres but remain predominantly rural, with $35 \%-46 \%$ urban population. Population density is relatively high (over 170 inhabitants per $\mathrm{km}^{2}$ in the urban districts, but substantially lower in rural districts). Fertility is below five children per woman in these regions, with the exception of Kaolack (5.2). These regions account for $31 \%$ of Senegal's population.

- Rural regions: The remaining regions have low urbanisation rates (15\%-26\%) and high fertility (5.1-6.4 children per woman). Four regions in the Centre and North (Diourbel, Fatick, Kaffrine and Louga) have long distances to facilities, with $18 \%-39 \%$ of women reporting distance as a barrier to accessing healthcare. This issue is more pronounced in five isolated rural regions in the East and South (Matam, Tambacounda, Kédougou, Kolda and Sédhiou) with very low population density and $36 \%-50 \%$ of women reporting distance as a barrier to access. Together, these nine rural regions account for $46 \%$ of Senegal's population.

Sources: Situation Economique et Sociale du Sénégal en $2016^{76}$ and 2017 Demographic and Health Survey. ${ }^{29}$

unskilled birth attendants), ${ }^{29}$ although increasingly also midwives (considered SBA). Health huts tend to be a single room with a bed staffed part time by community health agents such as matrones, funded by village health committees rather than the Ministry of Health and Social Action (MoHSA).

Maternal mortality in Senegal remained high at 315 per 100000 live births in 2017, down from 540 in $19900^{31}$ Improving maternal and newborn health is a political priority in Senegal, listed as the first objective of the 2009-18 National Health Development Plan. ${ }^{32}$ User fee exemptions for childbirth and caesareans were selectively introduced in $2005,{ }^{33}$ and expanded to include all public facilities, although some patient fees remain. Among subSaharan countries with Demographic and Health Survey (DHS) data, Senegal has the highest percentage of women delivering in facilities who report no skilled attendant (19\% in 2014), ${ }^{934}$ and the deficit of midwives was estimated at $50 \%$ of the need in $2013 .^{32}{ }^{35}$ Low availability of anticonvulsants for hypertensive disorders, manual vacuum extractors and provider CEmONC training have been highlighted as gaps in EmONC readiness. ${ }^{36}$

\section{Data sources}

We used data from nine DHS conducted in Senegal between 1992-1993 and 2017. The DHS are nationally representative, standardised surveys of women of reproductive age, collecting information on births and childbirth care. ${ }^{37}$ The four annual continuous DHS between 2012-2013 and 2016 had smaller sample sizes ${ }^{38}$ : we grouped the 2012-2013 and 2014 DHS, and the 2015 and 2016 DHS, to increase statistical power and generate regionally representative estimates.

To assess facility EmONC and referral readiness in hospitals, health centres, health posts and health huts, we used data on infrastructure, staffing and equipment for childbirth collected in the most recent SPA, a nationally representative survey of facilities of all sectors (public, private not-for-profit, private for-profit and private religious) ${ }^{39}$ Our study focuses on public facilities where $94 \%$ of facility births occur ${ }^{29}$; our sample includes 476 public facilities reporting to provide delivery care in the 2017 $\mathrm{SPA}^{40}$

Lastly, we used a geo-referenced MoHSA census of public facilities in Senegal, excluding health huts. ${ }^{41}$ Facility location was classified using a WorldPop population density raster. ${ }^{42}$ Facilities were considered urban if they were located in a $100 \mathrm{~m}^{2}$ grid square with population density above 10 , to maximise agreement with the SPA classification. We identified all public facilities (hospitals and health centres) performing caesareans in November 2018, using information from prior facilitybased studies, ${ }^{4344}$ the SPA, and key informants, including the MoHSA and Senegalese coauthors. Discrepancies between sources occurred for six facilities, which we resolved by contacting the relevant district medical officers.

\section{Analyses}

Detailed indicator definitions are included in online supplementary appendix 1 .

For each DHS, we estimated the percentage (and 95\% CI) of births by place and birth attendant among all live births in the 2 years prior to the survey, based on women's self-report. We also calculated the population caesarean section rate as a proportion of live births in the 2 years before the survey, as an indicator of CEmONC access. Our estimates are based on 31108 live births to 29938 women across the seven time points. We further tested differences in place of birth between the earliest (19921993) and most recent (2017) surveys using $X^{2}$ tests, and used United Nations Population Department data on population size and birth rate to estimate the average absolute number of births per year in the 2-year recall period of each time point. ${ }^{45} 46$

Using 2017 SPA data, we described facility readiness to provide routine childbirth care, EmONC and emergency referrals by facility level. Facilities were considered to provide BEmONC-1 if they reported ever providing and having available equipment for six signal functionsselected key interventions used to treat direct obstetric complications $^{47}$ (antibiotics, oxytocin, anticonvulsants, manual removal of placenta, removal of retained products and neonatal resuscitation; see online supplementary appendix 1). We excluded assisted vaginal delivery (by forceps or vacuum) from BEmONC signal functions 
due to data quality concerns. Facilities were considered to provide CEmONC-1 if they provided BEmONC-1 and both CEmONC signal functions (caesarean sections and blood transfusion). We calculated the median number of each provider cadre employed and total SBAs (doctors, midwives and nurses) by facility level and urban/rural location within the public sector. Facilities were considered to have adequate referral readiness if they had a vehicle available for referrals, or had a telephone available and reported access to a vehicle elsewhere. We estimated the percentage of public sector births occurring in facilities with different levels of EmONC or referral readiness by multiplying the percentage of facilities in each readiness category in each facility level by the corresponding percentage of women reporting to deliver in each health facility level in the 2017 DHS. We performed this calculation for all births in Senegal and by region.

All DHS and SPA analyses took into account survey weights, as well as clustering and stratification where appropriate.

We created maps showing the locations of public facilities with and without caesarean capacity using $\mathrm{R}^{48}$ Driving time to the nearest caesarean facility was estimated by calculating the driving time from facilities without caesarean capacity to each facility with caesarean capacity, and selecting the one with the shortest driving time. We used the OpenStreetMap-Based Routing Service (OSRM) package in $\mathrm{R},{ }^{49}{ }^{50}$ which allows for the computation of travel time between points based on assumptions relating to vehicle and road characteristics, such as average speed. ${ }^{51}$ Eighteen facilities had long estimated driving times ( $>3$ hours) most often due to lack of proximity to marked roads on OSRM; we replaced these with driving times reported by district medical officers in relevant districts (see online supplementary appendix 2, table $\mathrm{S} 1$ ). Lastly, we described urban-rural and regional variations in childbirth care utilisation and facility readiness.

\section{Patient and public involvement}

Patients or the public were not involved in the design, conduct, reporting or dissemination of our research.

\section{RESULTS}

\section{National trends in childbirth care utilisation over time}

The percentage of births in facilities in Senegal rose steadily from $47 \%$ of live births in 1992 to $80 \%$ in 2016 (see online supplementary table S2, figure 1). This 1.7fold increase corresponds to a threefold rise in the absolute number of facility births from 156000 to 465000 per year in the same period (online supplementary figure $\mathrm{S} 2$ ). Most of the rise in both urban and rural areas occurred in public health posts, which accounted for over $70 \%$ of the increase in facility births in this period $(\mathrm{p}<0.001$, online supplementary table S2). Births in public health centres increased by six percentage points $(p=0.001)$. There was no evidence of a national rise in births in public hospitals or non-public facilities; in fact, births in public hospitals declined by 10 percentage points among urban women $(\mathrm{p}=0.001)$. In 2016, public health posts accounted for $42 \%$ of all births (half of facility births), compared with $19 \%$ in public health centres and $11 \%$ in public hospitals. Under $5 \%$ of births occurred in each health huts and non-public facilities.

Trends in facility-based births were unequal across the country. Overall, women living in rural areas were more likely than urban women to deliver in lower-level facilities (53\% in health posts and huts compared with $34 \%$, respectively; figure 1 ). There was substantial regional variation: while $96 \%$ of women in Dakar gave birth in facilities in 2016, this figure was only $52 \%-56 \%$ in the rural South-East (figure 2B; see online supplementary table S3 for detailed regional breakdowns). The proportion of births taking place at different facility levels also varied throughout the country, with higher hospital delivery

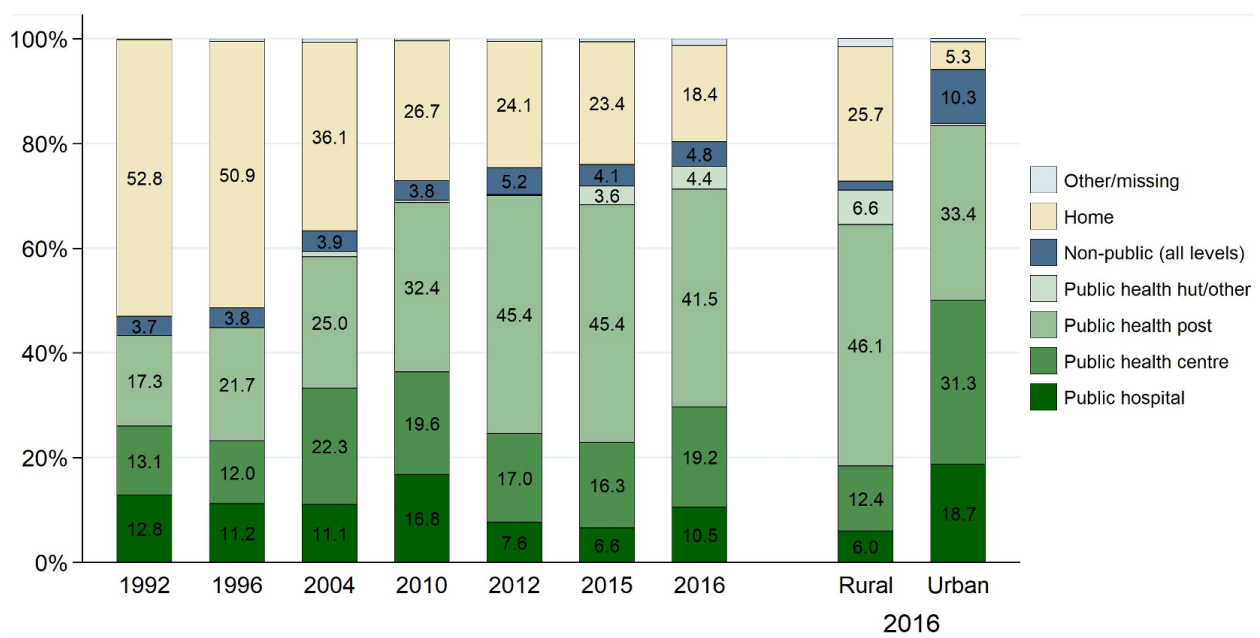

Figure 1 Place of delivery by DHS recall period midpoint in Senegal (all live births in 2-year recall period). Note: 'health hut' was not available as a response option before the $2015-2016$ DHS; percentages $<3 \%$ not labelled; non-public facilities include private for-profit, private not-for-profit and religious (all facility levels); the midpoint corresponds to the calendar year of the halfway point of the data collection period for each survey. DHS, Demographic and Health Survey. 
A. Births in urban areas (\% all births)

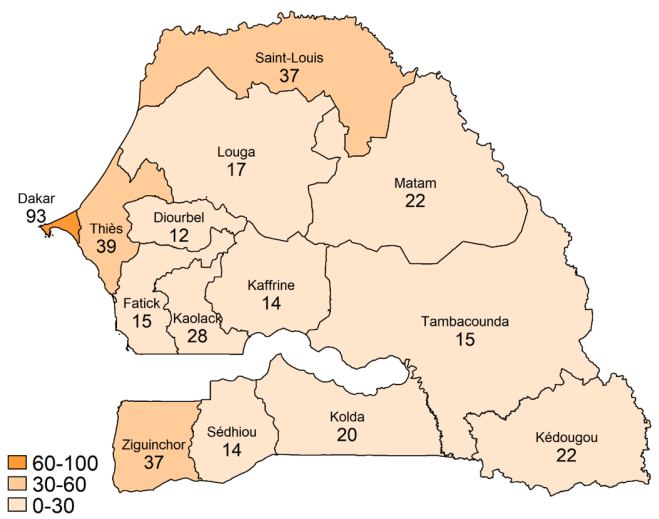

C. Caesarean section rate (\% all births)

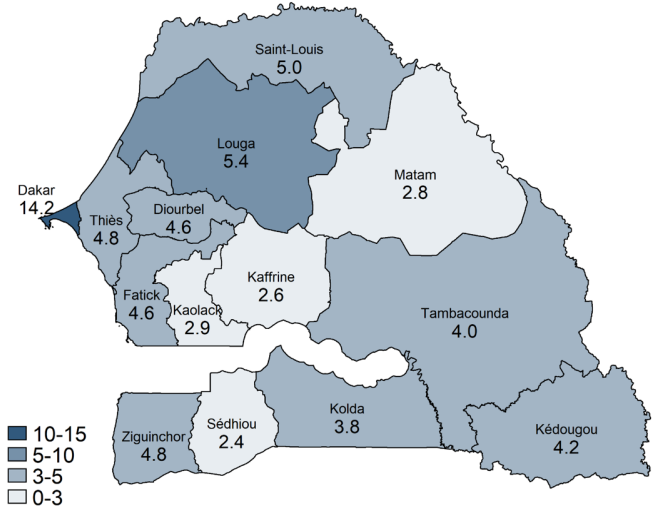

B. Facility births (\% all births)

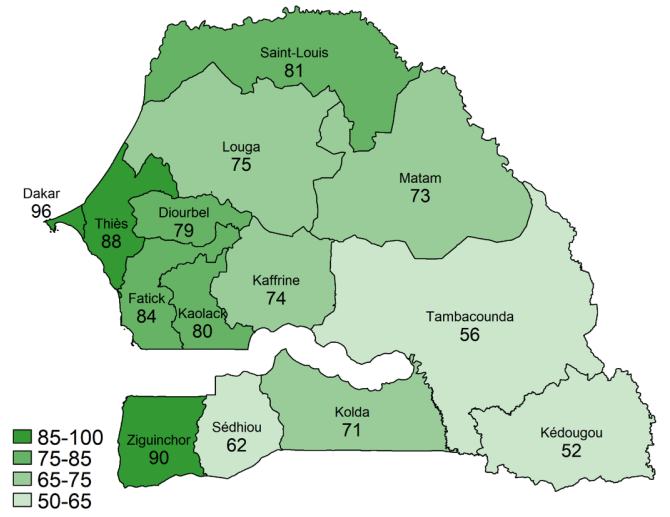

D. Births in facilities with safe childbirth conditions

(\% public sector births)

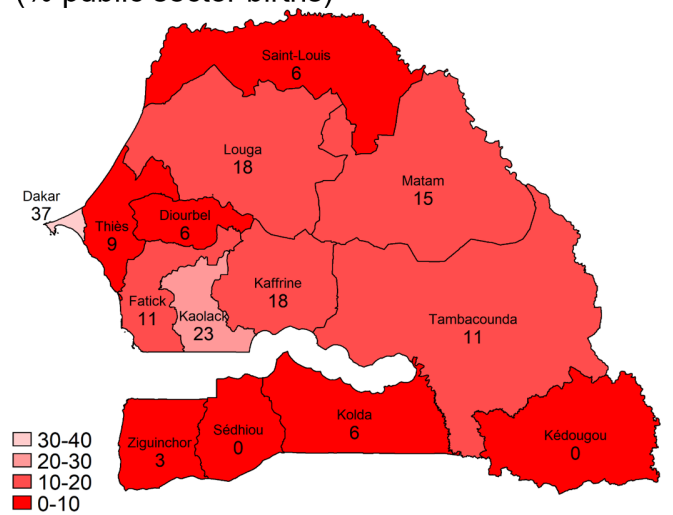

Figure 2 Childbirth care utilisation, facility readiness and birth outcomes by region in Senegal. Note: Safe childbirth conditions are defined as either full CEmONC-1 readiness (including all BEmONC-1 functions) or full BEmONC-1 readiness with adequate referral readiness (vehicle available on site or telephone available and reported access to vehicle elsewhere). Indicators A-C are calculated among births in the last 2 years from the 2017 DHS, and indicator D from analysis estimates (2017 percentage of deliveries by facility level multiplied by capacity categories within each level). BEmONC, basic emergency obstetric and newborn care; CEmONC, comprehensive emergency obstetric and newborn care; DHS, Demographic and Health Survey.

rates in the three most urbanised regions (Dakar, SaintLouis and Ziguinchor) and higher health hut deliveries in the Centre and South.

In 1992, the proportion of births attended by an SBA was identical to the proportion of facility births $(47 \%)$. However, by 2016 , only $71 \%$ of all births were reported to be assisted by an SBA, compared with $80 \%$ births in facilities (see online supplementary figure S1). Important fluctuations in self-reported birth attendant were observed between surveys. In 2016, $14 \%$ of women delivering in public facilities reported being assisted by a non-SBA (primarily matrones), including $14 \%$ in public health posts and $85 \%$ in public health huts (see online supplementary figure S3). Overall, $90 \%$ of births among urban womenbut only $60 \%$ among rural women-were attended by an SBA in 2016 (see online supplementary figure S1).

The national caesarean section rate more than doubled from $2.4 \%$ to $6.0 \%$ over 25 years $(\mathrm{p}<0.001$, online supplementary table S2), representing a fourfold absolute increase from 8000 to 35000 caesarean births per year. However, this increase was primarily driven by a rise in urban areas; although they are still lagging behind, the caesarean rate also increased from $1.7 \%$ to $3.7 \%$ in rural areas (see online supplementary table S2). In 2016, $14 \%$ of births were by caesarean in Dakar, compared with at most $5 \%$ in all other regions (figure $2 \mathrm{C}$ ).

\section{Facility readiness for EmONC and staffing at different levels of the public health system}

Around $85 \%$ of hospitals and health centres reported providing childbirth care in 2017, compared with 93\% of health posts and less than half of health huts (see online supplementary table S4).

Combined readiness for all BEmONC-1 functions was only $8 \%-10 \%$ in health posts, $26 \%-28 \%$ in health centres and $40 \%$ in hospitals (table 1 , figure $3 \mathrm{~A}$ ). There was little difference in BEmONC-1 readiness between urban and rural health centres and posts; it was strikingly low both in the capital $(24 \%)$ and other regions (0 in two rural Southern regions; online supplementary table S3). Overall, only $17 \%$ of public sector births in Senegal occur in facilities able to provide all BEmONC-1 functions. Readiness for anticonvulsants, manual removal of placenta and removal of retained products was particularly low in health centres and posts; only two-thirds of hospitals had readiness to provide antibiotics. Only $2 \%$ of 


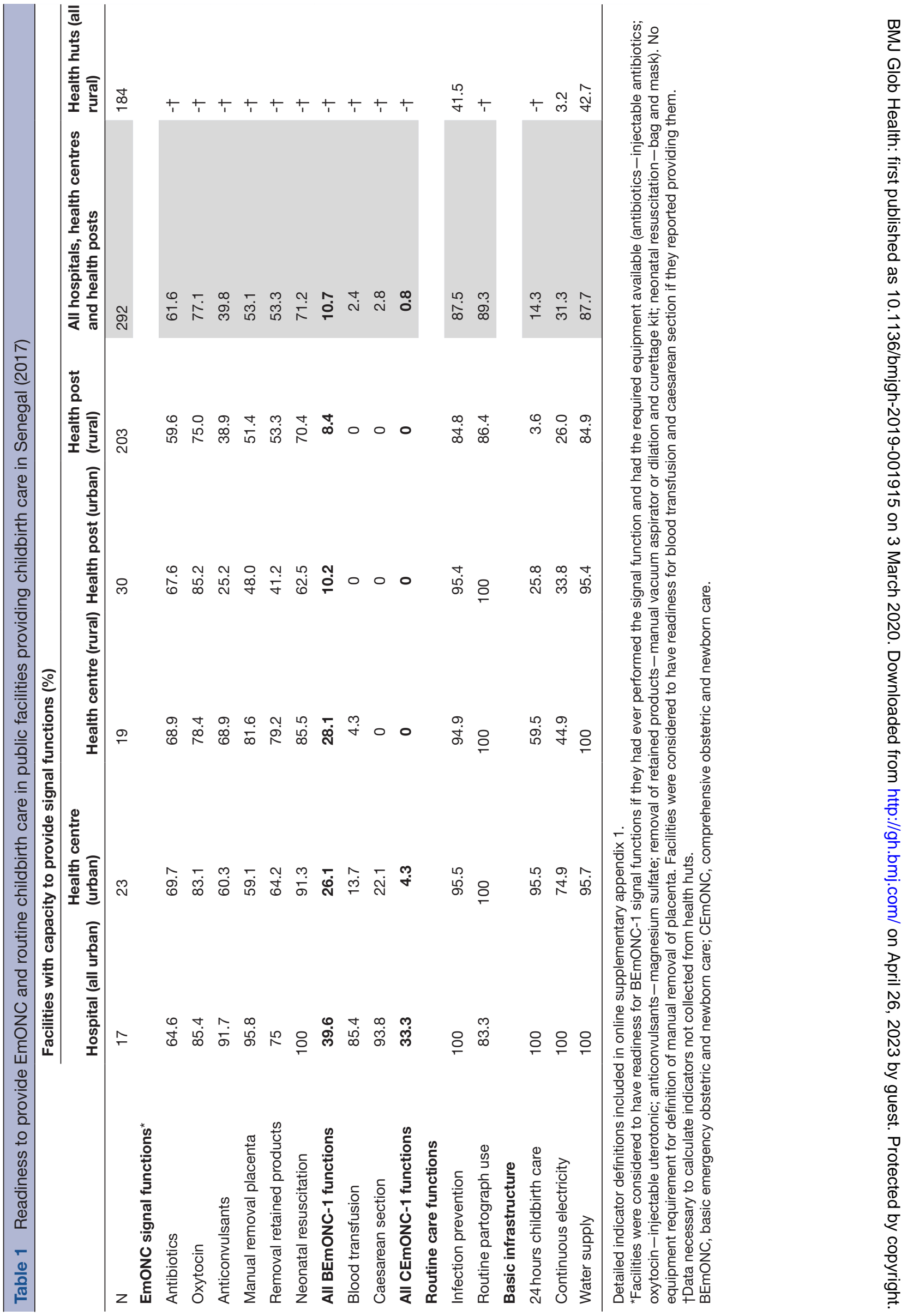


A. Readiness for emergency obstetric and newborn care (EmONC)

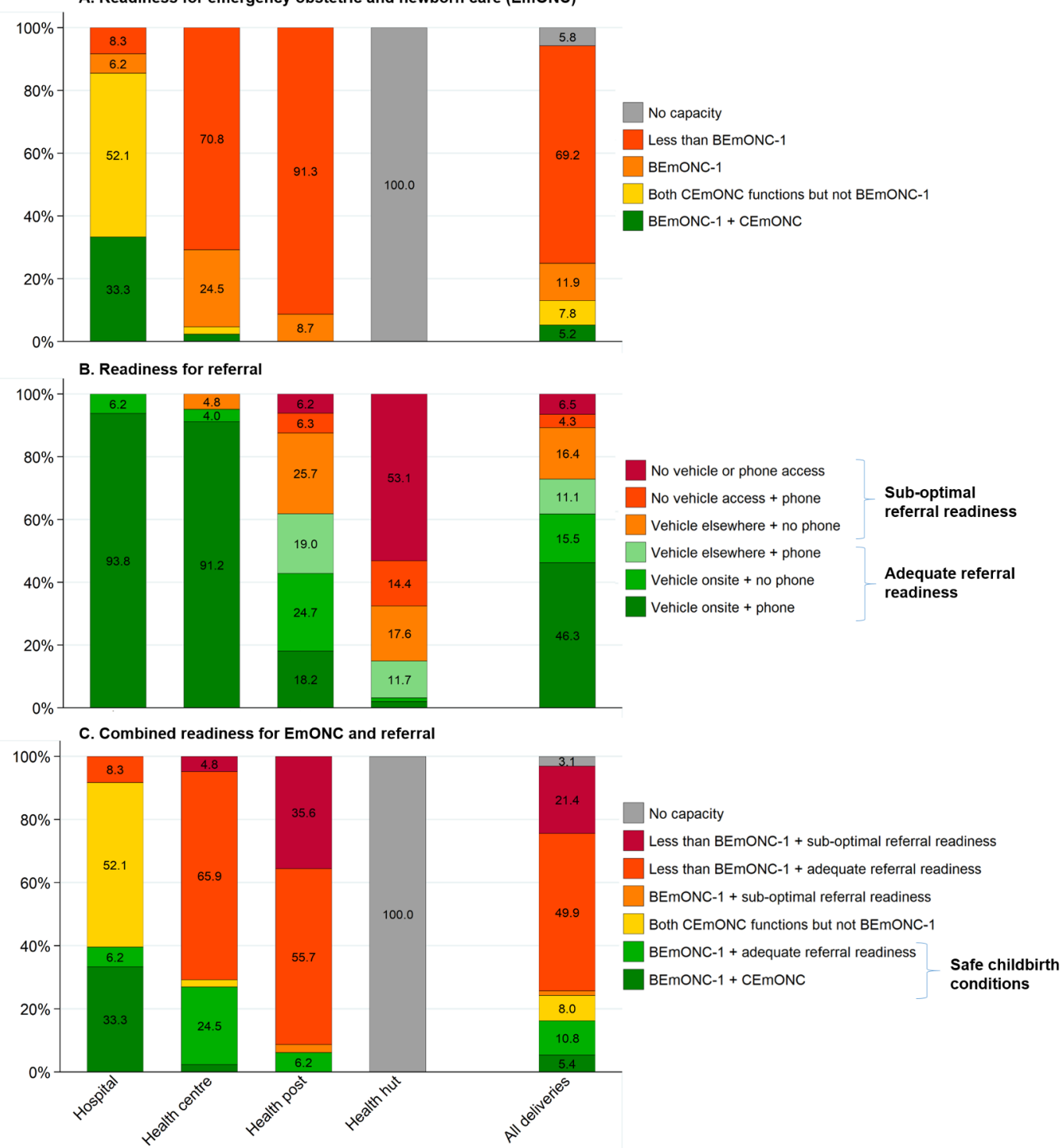

Figure 3 Readiness for emergency obstetric care and referral in public facilities, and among all deliveries in public facilities, in Senegal (2017). The order of categories in the legend reflects the order in stacked bars. BEmONC, basic emergency obstetric and newborn care; CEmONC, comprehensive emergency obstetric and newborn care.

public health centres and one third of hospitals had full CEmONC-1 readiness, although 15 of the 17 hospitals performed both CEmONC functions (caesarean section and blood transfusion, regardless of BEmONC capacity; table 1).

Readiness to provide routine childbirth care was also poor in lower-level public facilities (table 1). Infection prevention, routine partograph use and water supply were relatively available, but 24 hour childbirth care and continuous electricity were especially low in rural health posts ( $4 \%$ and $26 \%$, respectively). Data on EmONC readiness were not collected from health huts, since they are not expected to have BEmONC capacity; however, continuous electricity $(3 \%)$, infection prevention measures $(42 \%)$, and water supply (43\%) were suboptimal.

Of 1259 public facilities in the national census, we identified 40 with functional caesarean capacity in November 2018, with unequal regional distribution (12 in the
Dakar region, compared with only one in each of four regions in the Centre and South). Facilities performing caesareans were concentrated in urban areas with higher pregnancy density, and vast rural areas lacked caesarean coverage, particularly in Northern, Eastern and SouthEastern regions (figure 4A).

Staffing varied substantially according to public facility level (see online supplementary table S5). No SBAs were employed in health huts. Although all facilities above health huts employed at least one SBA, rural health posts had very low staff numbers, with a median of one nurse and one midwife, and $30 \%$ did not employ a midwife. In contrast, urban health posts employed a median of two nurses and two midwives. Hospitals and health centres had higher median staff numbers and more variability, with a median of at least two doctors and four midwives in rural and urban facilities. 
A. Distribution of public facilities with and without caesarean capacity

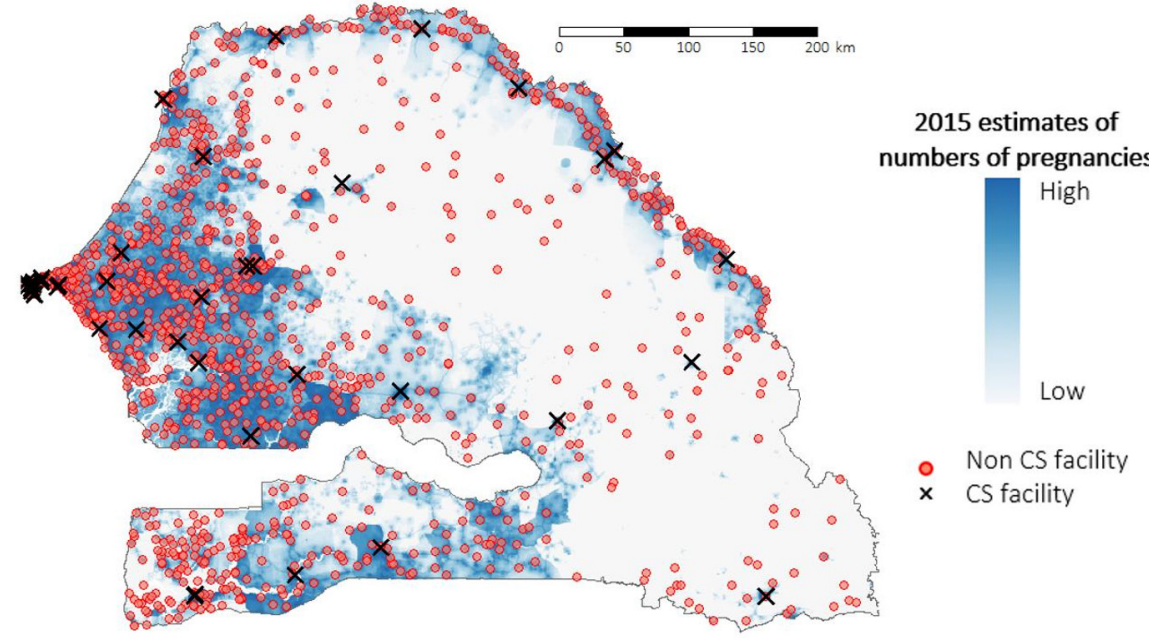

B. Driving time to nearest public facility with caesarean capacity (public facilities without capacity)

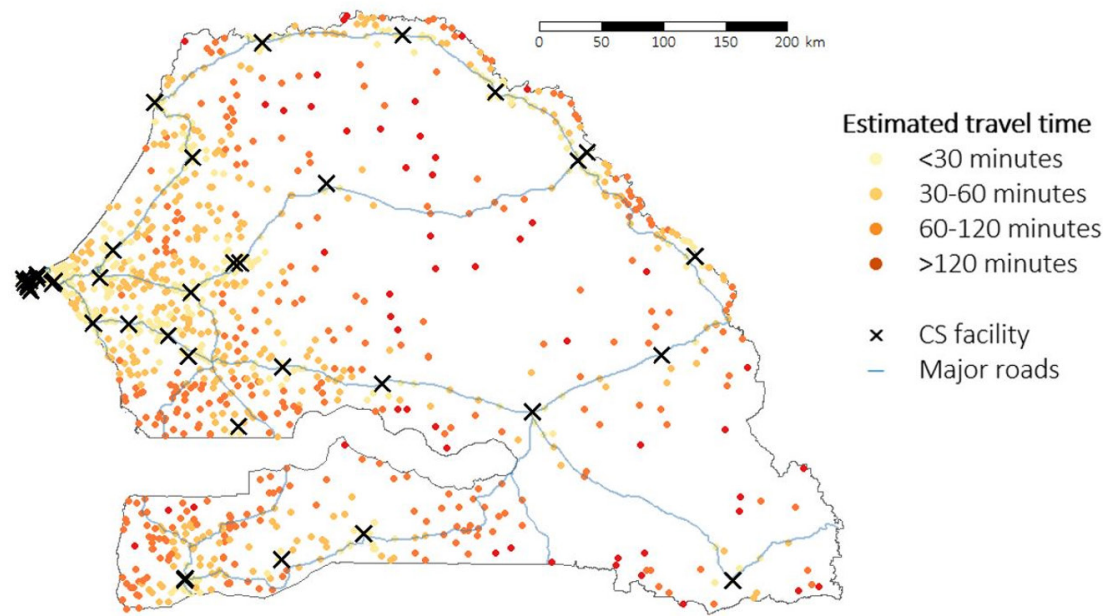

Figure 4 Geographical distribution and driving time from public facilities without $(n=1219)$ to facilities with ( $n=40)$ capacity to provide caesarean care in Senegal. CS facility - facility with caesarean capacity; non-CS facility - facility without caesarean capacity. Sources: WorldPop $1 \mathrm{~km}$ pregnancy density estimates ${ }^{77}$ and Ministry of Health and Social Action National health facility census. ${ }^{41} \mathrm{CS}$, caesarean section.

\section{Readiness for emergency referrals}

Adequate referral readiness-defined as either on-site vehicle access, or telephone with remote vehicle accesswas $100 \%$ in hospitals and $95 \%$ in health centres, but only $62 \%$ in health posts and $15 \%$ in health huts (figure $3 \mathrm{~B}$ ). Overall, $73 \%$ of public sector births occurred in facilities with adequate referral readiness. Striking regional variation was observed, from $12 \%$ of facilities in rural Kolda to 91\% in Ziguinchor (see online supplementary table S3), and $12 \%-13 \%$ of health posts had no access to a referral vehicle (table 2). Only $3 \%$ of health huts reported a vehicle on-site, and two-thirds lacked any formal vehicle access.

Among public health centres and posts without caesarean capacity, the nearest facility performing caesareans was located at a median distance of $32 \mathrm{~km}$, or $41 \mathrm{~min}$ ' driving time (table 2). Median driving times were much higher for rural health centres and posts (47-48 min) than urban facilities $(6-10 \mathrm{~min})$. More than one-third of rural health posts and one-quarter of rural health centres were located at least 1-hour driving time from the nearest caesarean facility. Important geographical differences in driving times were observed (figure 4B); the median ranged from $5 \mathrm{~min}$ in Dakar to 1 hour 40min in rural South-Eastern Kédougou (see online supplementary table S3).

\section{Combined EmONC and emergency referral readiness}

Overall, $40 \%$ of public hospitals, $29 \%$ of public health centres and $6 \%$ of public health posts were able to provide minimum safe childbirth conditions (either full CEmONC-1, or BEmONC-1 with adequate referral readiness; figure 3C). This figure was higher in urban (14\%) than rural areas $(3 \%)$ for all facilities; around $16 \%$ of all public sector births in Senegal occurred in such facilities. Dakar was the best performing region (37\% of births in facilities meeting minimum safe conditions, with $18 \%$ of births nationally) compared with less than $10 \%$ in seven 
Table 2 Referral readiness in public facilities providing childbirth care in Senegal

\begin{tabular}{|c|c|c|c|c|c|c|c|c|c|}
\hline \multirow[b]{3}{*}{ Data source } & \multirow[b]{3}{*}{$\mathbf{N}$} & \multicolumn{4}{|l|}{ SPA } & \multirow[b]{3}{*}{$\mathbf{N}$} & \multirow{2}{*}{\multicolumn{3}{|c|}{$\begin{array}{l}\text { MoHSA health facility census } \\
\text { Access to closest facility performing caesareans, } \\
\text { among facilities without caesarean capacity }\end{array}$}} \\
\hline & & \multirow[b]{2}{*}{$\begin{array}{l}\text { Telephone } \\
\text { availability* } \\
(\%)\end{array}$} & \multicolumn{3}{|c|}{ Vehicle access† (\%) } & & & & \\
\hline & & & On-site & $\begin{array}{l}\text { At other } \\
\text { facility }\end{array}$ & None & & $\begin{array}{l}\text { Median road } \\
\text { network distance } \\
\text { (IQR) }\end{array}$ & $\begin{array}{l}\text { Median direct travel } \\
\text { time (IQR) }\end{array}$ & $\begin{array}{l}\% \text { within } \\
\text { 1-hour } \\
\text { driving } \\
\text { time }\end{array}$ \\
\hline Health centre (rural) & 19 & 85 & 89 & 11 & 0 & 34 & $\begin{array}{l}44 \mathrm{~km} \\
(27 \mathrm{~km}-59 \mathrm{~km})\end{array}$ & $\begin{array}{l}48 \mathrm{~min} \\
(28 \mathrm{~min}-1 \text { hour } 10 \mathrm{~min})\end{array}$ & 74 \\
\hline Health post (urban) & 30 & 34 & 37 & 51 & 12 & 185 & $\begin{array}{l}4 \mathrm{~km} \\
(2 \mathrm{~km}-9 \mathrm{~km})\end{array}$ & $\begin{array}{l}6 \min \\
(4 \min -12 \mathrm{~min})\end{array}$ & 96 \\
\hline Health hut (all rural) & 184 & 28 & 3 & 29 & 68 & 0 & $-\S$ & $-\S$ & $-\S$ \\
\hline
\end{tabular}

Sources: Senegal 2017 SPA $^{78}$ and MoHSA National health facility census. ${ }^{41}$

${ }^{*}$ Functional landline or mobile phone paid for by the facility.

†Any vehicle used for transporting patients, mutually exclusive categories (facilities with vehicle access on-site are not asked about vehicle access at other facility)

¥Only two hospitals did not have caesarean capacity, both specialised hospitals in Dakar within 3 min of a hospital with caesarean capacity

$\S$ Health huts are funded by the community rather than the MoHSA; they do not appear in the MoHSA health facility census.

MoHSA, Ministry of Health and Social Action; SPA, Service Provision Assessment.

rural regions, collectively accounting for $46 \%$ of all births in Senegal (see online supplementary table S3).

\section{DISCUSSION}

Using DHS and SPA data as well as a national census of health facilities in Senegal, we found that lower-level health posts and huts-where the majority of facility births occur-lack the emergency obstetric care and referral readiness to provide high-quality, timely care to women and babies during childbirth. Over the 25 years between 1992 and 2016, facility births rose from $47 \%$ to $80 \%$, representing a threefold increase in absolute numbers-from 156000 to 465000 annually. This is a substantial achievement for the MoHSA and reproductive health partners. However, most of this increase occurred through women's utilisation of lower-level health posts and huts, accounting for $46 \%$ of all births or 266000 births in 2016. Readiness for emergency obstetric care and referral declined steeply from health centres to health posts, and health huts, and only $16 \%$ of public facility births occurred in facilities able to provide safe childbirth conditions. Moreover, an estimated $14 \%$ of facility deliveries-or 64000 deliveries in 2016-took place with an unskilled matrone, the highest percentage in sub-Saharan Africa. ${ }^{9}$ Improvements in caesarean section rates were concentrated in urban areas, indicating that rising facility births did not greatly improve access to emergency obstetric and newborn care in rural areas. In line with previous studies finding substantially lower effective than crude coverage of childbirth care, ${ }^{18}{ }^{52-54}$ these findings raise important concerns about the quality of care provided to women in Senegalese facilities, and elsewhere in sub-Saharan Africa.

Women in rural areas are particularly affected by low facility readiness. In urban areas, $50 \%$ of women give birth in larger hospitals and health centres, and more facilities are able to provide safe childbirth conditions (14\% compared with $3 \%$ in rural areas). The caesarean rate of $10 \%$ suggests that women are usually able to reach a higher-level facility when needed: although the referral system is reportedly ineffective-many referrals take place with taxis or private vehicles-in urban areas some women can bypass the formal referral system with their own means thanks to proximity to higher-level facilities (median driving time of 6-10 min, with important differences between regions). In contrast, more than half of rural women give birth in health posts and huts, and onequarter at home. One-third of rural health posts employ only one nurse, with no midwife. Although EmONC and referral readiness were similarly low in urban and rural health centres and posts, consequences for maternal and perinatal health are much more severe in rural areas, where distances to the nearest CEmONC facility are substantially longer and alternative transport means less available. The situation is even more concerning in community-owned rural health huts, where $4 \%$ or 25000 births occur annually: health huts do not employ skilled attendants, EmONC is not available, and two-thirds do 
not have adequate referral readiness. The caesarean rate below $4 \%$ among rural women-and at most $5 \%$ in all regions outside Dakar-highlights an unmet need for life-saving EmONC ${ }^{55}$ despite the substantial increase in facility births, and suggests that the referral system is not optimal in rural areas. There are no accepted guidelines for maximum duration of obstetric referrals in highincome or low-income countries; however, obstetricians' associations in the UK and USA have targets of $30 \mathrm{~min}$ decision-to-delivery intervals for caesarean sections for foetal compromise. ${ }^{5657}$ This is an unattainable target for the vast majority of women delivering in rural facilities, with median driving times of over 45 min to the nearest caesarean facility.

Reliable subnational estimates are not available; however, women from isolated rural areas likely contribute disproportionately to maternal deaths and stillbirths. Improvements in women's EmONC access in urban areas likely contributed to the $40 \%$ reduction in maternal mortality in Senegal since $1990^{31}$ : to accelerate progress and meet SDG targets, Senegal must now address gaps in emergency obstetric care and referral in rural areas. Our study found important gaps in treatment of hypertensive diseases and haemorrhage in particular, which account for $14 \%$ and $27 \%$ of maternal deaths, respectively. ${ }^{58}$ Other studies in sub-Saharan Africa also found that $\mathrm{BEmONC}$ readiness is low in lower-level facilities as well as higher-level facilities with caesarean or blood transfusion capacity; in particular, assisted vaginal deliveries are often unavailable. ${ }^{1659}{ }^{60}$ Poor BEmONC readiness is problematic because early detection and management of complications is essential for preventing a need for higher-level care and severe maternal outcomes. For example, uterotonic drugs and manual removal of retained placenta can stop postpartum haemorrhage early and prevent the need for urgent blood transfusion or hysterectomy. BEmONC readiness is therefore particularly valuable in the context of long travel times to referral facilities. A recent study in Ghana found that facility birth without EmONC capacity does not necessarily reduce maternal or perinatal mortality. ${ }^{7}$

Facility staffing and readiness estimates in health posts and huts likely represent the best-case scenarios. Although facilities may have the equipment needed and have provided a signal function previously, it does not ensure such care is provided in a timely manner to all women who need it. The number of SBAs employed in health posts-particularly rural ones-is insufficient to ensure skilled attendance to all women during childbirth. Although $99 \%$ of health posts employ a nurse in-charge (considered an SBA), competing clinical responsibilities for outpatient consultations mean no SBAs are dedicated solely to delivery care. In 2013, the deficit of midwives in Senegal was estimated at around $50 \%$ of total need for workforce time. ${ }^{32}{ }^{35}$ The MoHSA travelling midwives initiative $^{61}$ and recruitment efforts under the National Family Planning Action Plans ${ }^{62}$ have led to a substantial rise from $48 \%$ health posts employing midwives in 2014 to $75 \%$ in 2017 . However, it is likely to have a limited impact on quality of childbirth care in health posts with limited EmONC readiness. In such circumstances, the capacity for timely and effective transfer to hospital is critical to the reduction of maternal and perinatal mortality, particularly in rural areas.

Emergency referral readiness was lacking in many health posts and huts. In practice, providers may use personal mobile phones to contact referral facilities; however, such informal pathways are problematic for rapidly requesting ambulances and warning the referral facility of incoming referrals. Vehicle availability may also be overestimated in health posts, where they are also used for outreach and administrative duties, and may not always be available or have petrol when needed. Total referral time for facilities without a vehicle includes time to request an ambulance (usually from the referral facility), for the ambulance to arrive and drive to the referral facility. Therefore, total time for the woman to reach the referral facility is likely substantially longer than the estimated median driving time of $41 \mathrm{~min}$. Similar gaps in referral systems have also been noted in Tanzania. ${ }^{63}$

\section{Limitations}

Our study has some limitations. We focused on childbirth care, known to be crucial for the survival of women and babies, although antenatal and postnatal care are also essential. Similarly, we reported access to facilities performing caesareans as a proxy for advanced EmONC, because surgical capacity is more easily ascertainable, although other EmONC interventions (including blood transfusions) are equally critical. We did not assess readiness in non-public facilities, where only $5 \%$ of births occur in Senegal.

Unlike in other countries, the Senegal SPA did not collect the number of deliveries in each facility. We were thus unable to calculate results weighted by delivery volume. However, we used the percentage of women giving birth in each facility level and readiness level as proxies. Facilities appeared to misreport assisted vaginal delivery (over $90 \%$ of health huts reported having performed forceps or vacuum deliveries); we therefore excluded it from our BEmONC estimates. Our definition of BEmONC signal functions based on facilities having ever provided them probably overestimates readiness; however, restricting to performance in the last 3 months would introduce bias since lower-level facilities with fewer patients might not have needed to provide signal functions within this period. Our categories of facilitylevel mask important differences in facility environment between, for example, health centres in Dakar and isolated rural districts.

Women may have misreported their birth attendant, probably overestimating their qualification, ${ }^{64}$ as highlighted by fluctuations in SBA between 2010 and 2016, probably too large to reflect true changes over this short period. The combined percentage of SBA cadres and matrones shows a slow and steady increase over time, 
suggesting matrones are mistaken for SBAs by some women, including the $14 \%$ of women delivering in health huts who reported SBA. Observations would provide a better understanding of who assisted women during childbirth than the DHS or SPA, however, women's reports in the DHS align with staff numbers and responsibilities in facilities in the SPA, suggesting that unskilled attendants assist a non-negligible percentage of facility births in Senegal. Women are less likely to misreport facility level. ${ }^{65}$

Lastly, OpenStreetMap algorithms are based on assumptions of vehicle speed which may underestimate driving time in the rainy season or peak traffic hours, and overestimate driving time where no marked roads exist. Driving times are likely much greater for health huts than health posts. Use of district medical officer reports for the 18 facilities with long driving time estimates is imprecise, although it is unlikely to have biased median driving times since both modelled and reported estimates were above the upper quartile. Our estimates represent driving times to facilities performing caesareans, and may underestimate driving time to facilities with other advanced EmONC services.

\section{Implications for policy and programmes}

We echo the call from the 2016 Lancet series that it is unethical to encourage women to give birth in places with low facility capability, no referral mechanism, with unskilled providers, or where content of care is not evidence based. ${ }^{9}$ Women should be urgently encouraged to deliver in health centres and hospitals, ${ }^{5}$ with the aim of shifting the majority of deliveries away from health posts not meeting requirements for safe delivery and referral, and actively discouraged from delivering in health huts. Commensurate improvements in capacity (including staff, maternity beds and equipment) must be made in hospitals and health centres to accommodate this substantial number of additional deliveries. Health hut readiness is not meaningfully different from home environments, therefore, births in health huts should not be included in Senegal's facility births estimates.

The biggest challenge facing Senegal-and many countries in Sub-Saharan Africa-is how to provide highquality childbirth care to women in rural areas with low population density, high fertility rates and long distances to facilities. Determining where the balance should lie between bringing delivery care closer to women in lower-level facilities with lower capacity (such as health posts), and centralising material and human resources in health centres and hospitals while improving referrals from lower-level facilities, needs to occur in a considered manner and on a region-by-region basis. ${ }^{66}$ The 2009-2018 National Health Development Plan aimed for surgery to be available in all health centres ${ }^{32}$; however, selectively upgrading health centres based on driving time to nearest facility with caesarean capacity is likely a better use of resources. Overcoming distance to facilities in rural areas is one of the greatest challenges in sub-Saharan Africa. Although the Lancet Quality Care
Commission recommends centralising deliveries in hospitals ${ }^{12}$ this is currently unattainable in the most rural regions in Senegal, and a gradual shift away from health posts to health centres is more realistic. The challenge of childbirth care coverage is unlikely to be addressed by the health sector alone, as demonstrated by China's achievements in lowering maternal mortality in rural provinces through additional focus on roads, women's education and poverty reduction. ${ }^{67}$

Multisectoral interventions are needed to improve emergency referral readiness as the first priority in rural areas, where most births occur in lower-level facilities unable to provide CEmONC. All health posts should be equipped with telephones, and formalised communication protocols for referring and referral facilities should be developed and implemented. ${ }^{22}$ Subnational budgets should prioritise paving roads from health posts to main roads, and additional interventions should be trialled, including strategically placed shared ambulances and maternity waiting homes adjacent to health centres and hospitals. ${ }^{22} 6869$ Strengthening antenatal care would enable referral to higher-level facilities for women with preidentifiable conditions (including twin pregnancy and pre-eclampsia).$^{70-72}$ The extent of informal use of health services between Senegal and neighbouring Gambia is unknown; however, providers in Senegal are unable to refer to facilities in the Gambia, even if those are nearer: reciprocal formal arrangements between these countries for obstetric emergencies should be considered.

Moreover, EmONC readiness should be improved through equipment availability and regular training and supervision at all health system levels, particularly health posts in the short term and health centres as deliveries shift to this facility level. Additional investment in human resources are needed, particularly in rural facilities. Improving quality of care is a huge challenge requiring substantial financial and programme investments from the Senegalese government and reproductive health partners. Improving access to safe abortion in addition to existing contraception efforts, ${ }^{73} 74$ and increasing female education, would help prevent higher-risk births and abortion-related mortality.

As highlighted previously, the percentage of births in facilities alone is limited in its ability to track progress in effective coverage of childbirth care. ${ }^{75}$ Facility readiness surveys should be conducted routinely alongside population-based surveys, and every effort should be made to report the percentage of facilities providing minimum safe childbirth conditions and of births in such facilities-in addition to the commonly reported facility births and EmONC facilities per population ${ }^{11}$ - to improve quality of care for women and newborns globally.

\section{CONCLUSIONS}

Over the last quarter century, the Senegalese health system has accommodated a threefold increase in annual number of facility deliveries, predominantly by caring 
for women in public lower-level health posts. However, our findings show that the majority of women giving birth in health facilities are not meaningfully captured in a health system capable of providing high-quality care and timely referral for obstetric emergencies. Women in rural areas are particularly underserved as a result of long distances to CEmONC facilities, and likely contribute disproportionately to persistent high maternal and perinatal mortality despite increases in facility deliveries. This case study illustrates that promoting births in lower-level facilities might not produce care of adequate quality or timeliness in other sub-Saharan countries adopting similar national strategies. The global health community needs to expand indicators beyond facility deliveries and SBA to capture the quality of care women receive at birth, including the percentage of facilities providing safe childbirth conditions and the percentage of births in such facilities, as proposed in this article. The Senegalese government's commitment to reducing maternal mortality is noteworthy-to accelerate reductions in maternal and perinatal mortality, there is now an urgent need to improve referral readiness in rural facilities and EmONC readiness across all facilities, as well as to put policies in place which encourage women to deliver in health centres and hospitals.

\section{Author affiliations \\ ${ }^{1}$ CEPED, Institut de Recherche Pour le Développement, Paris, France \\ ${ }^{2}$ Institute of Child Health, University College London, London, UK \\ ${ }^{3}$ Department of Public Health, Institute of Tropical Medicine, Antwerp, Belgium \\ ${ }^{4}$ Faculty of Epidemiology and Population Health, London School of Hygiene and \\ Tropical Medicine, London, UK \\ ${ }^{5}$ Plan International Canada, Ottawa, Ontario, Canada \\ ${ }^{6}$ Institute of Social and Cultural Anthropology, Oxford University, Oxford, UK ${ }^{7}$ Institut de Santé et Développement, Université Cheikh Anta Diop, Dakar, Senegal ${ }^{8}$ IRESSEF: Institut de Recherche en Santé, de Surveillance Epidémiologique et de Formations, Dakar, Senegal \\ ${ }^{9}$ Medical Research Council Unit in The Gambia at the London School of Hygiene \& Tropical Medicine, Fajara, The Gambia}

Twitter El Hadji Dioukhane @dioukhane and Kerry Wong @kerrylmwong

Acknowledgements We thank the women and health facility staff who participated in the DHS and SPA surveys, and the DHS Programme for making these data available. We are also grateful to the Ministry of Health and Social Action for helping us compile the list of facilities performing caesareans, to MEASURE Evaluation for sharing data from the Urban Reproductive Health Initiative evaluation, and to the District Medical Officers who verified caesarean capacity and driving times to referral facilities in their districts. We are thankful to Siri Suh for the inspiration for the title of this article (see reference number 74).

Contributors FLC, LB, MM-A and PS conceptualised the study, and designed the analyses with additional input from EHD and CR. KW, ER, LB and FLC prepared the databases. FLC, AF, EHD and AD compiled the list of facilities performing caesareans, and EHD and AF vetted data sources. FLC and KW conducted the data analysis, all authors including ASM contributed to the interpretation of results. FLC drafted the full manuscript, all authors edited the manuscript. All authors approved the final version of the manuscript.

Funding Some authors of this study were supported by funding from MSD, through its MSD for Mothers programme (https://merckformothers.com). Funding was used for general financial support, including staff salaries, travel and overhead. MSD had no role in the design, collection, analysis and interpretation of data, in writing of the manuscript, or in the decision to submit the manuscript for publication. MSD for Mothers is an initiative of Merck \& Co., Kenilworth, New Jersey, USA.
Disclaimer The content of this publication is solely the responsibility of the authors and does not represent the official views of MSD.

Competing interests None declared.

Patient consent for publication Not required.

Ethics approval This study was approved by the Ethics Committee of the London School of Hygiene \& Tropical Medicine.

Provenance and peer review Not commissioned; externally peer reviewed.

Data availability statement Data may be obtained from a third party and are not publicly available. Access to data from the Demographic and Health Surveys and Service Provision Assessments can be requested on the website https:// dhsprogram.com/.

Open access This is an open access article distributed in accordance with the Creative Commons Attribution Non Commercial (CC BY-NC 4.0) license, which permits others to distribute, remix, adapt, build upon this work non-commercially, and license their derivative works on different terms, provided the original work is properly cited, appropriate credit is given, any changes made indicated, and the use is non-commercial. See: http://creativecommons.org/licenses/by-nc/4.0/.

\section{ORCID iDs}

Francesca L Cavallaro http://orcid.org/0000-0002-9641-8780

Kerry Wong http://orcid.org/0000-0002-4400-2257

Emma Radovich http://orcid.org/0000-0002-8975-8015

\section{REFERENCES}

1 UNECA, AU, ADB. MDG report 2015: assessing progress in Africa toward the millennium development goals. Addis Ababa, Ethiopia: United nations economic Commission for Africa, African Union, African development bank and United nations development programme, 2015. Available: http://www.undp.org/content/undp/en/ home/librarypage/mdg/mdg-reports/africa-collection.html [Accessed Nov 2019].

2 Alkema L, Chou D, Hogan D, et al. Global, regional, and national levels and trends in maternal mortality between 1990 and 2015, with scenario-based projections to 2030: a systematic analysis by the un maternal mortality estimation Inter-Agency group. Lancet 2016;387:462-74.

3 Blencowe $\mathrm{H}$, Cousens S, Jassir FB, et al. National, regional, and worldwide estimates of stillbirth rates in 2015, with trends from 2000: a systematic analysis. Lancet Glob Health 2016;4:e98-108.

4 The Inter-agency Group for Child Mortality Estimation (UN IGME), UNICEF, WHO. Levels and trends in child mortality. Report 2015. New York, USA: UNICEF, 2015. Available: https://childmortality. org/files_v20/download/IGME\%20Report\%202015_9_3\%20LR\% 20Web.pdf [Accessed Nov 2019].

5 Montagu D, Sudhinaraset M, Diamond-Smith N, et al. Where women go to deliver: understanding the changing landscape of childbirth in Africa and Asia. Health Policy Plan 2017;32:1146-52.

6 Kunkel M, Marete I, Cheng ER, et al. Place of delivery and perinatal mortality in Kenya. Semin Perinatol 2019;43:252-9.

7 Gabrysch S, Nesbitt RC, Schoeps A, et al. Does facility birth reduce maternal and perinatal mortality in Brong Ahafo, Ghana? A secondary analysis using data on 119244 pregnancies from two cluster-randomised controlled trials. Lancet Glob Health 2019;7:e1074-87.

8 Miller S, Abalos E, Chamillard M, et al. Beyond too little, too late and too much, too soon: a pathway towards evidence-based, respectful maternity care worldwide. Lancet 2016;388:2176-92.

9 Campbell OMR, Calvert C, Testa A, et al. The scale, scope, coverage, and capability of childbirth care. Lancet 2016;388:2193-208.

10 Campbell OMR, Graham WJ. Strategies for reducing maternal mortality: getting on with what works. Lancet 2006;368:1284-99.

11 Moller A-B, Newby H, Hanson C, et al. Measures matter: a scoping review of maternal and newborn indicators. PLoS One 2018;13:e0204763.

12 Kruk ME, Gage AD, Arsenault C, et al. High-Quality health systems in the sustainable development goals era: time for a revolution. Lancet Glob Health 2018;6:e1196-252.

13 Kozuki N, Oseni L, Mtimuni A, et al. Health facility service availability and readiness for intrapartum and immediate postpartum care in Malawi: a cross-sectional survey. PLoS One 2017;12:e0172492.

14 Kanyangarara M, Chou VB, Creanga AA, et al. Linking household and health facility surveys to assess obstetric service availability, 
readiness and coverage: evidence from 17 low- and middle-income countries. J Glob Health 2018;8:010603.

15 Cranmer JN, Dettinger J, Calkins K, et al. Beyond signal functions in global obstetric care: using a clinical cascade to measure emergency obstetric readiness. PLoS One 2018;13:e0184252.

16 Winter R, Yourkavitch J, Wang W, et al. Assessment of health facility capacity to provide newborn care in Bangladesh, Haiti, Malawi, Senegal, and Tanzania. J Glob Health 2017;8.

17 Kruk ME, Leslie HH, Verguet S, et al. Quality of basic maternal care functions in health facilities of five African countries: an analysis of national health system surveys. Lancet Glob Health 2016;4:e845-55.

18 Wang W, Mallick L, Allen C, et al. Effective coverage of facility delivery in Bangladesh, Haiti, Malawi, Nepal, Senegal, and Tanzania. PLoS One 2019;14:e0217853.

19 Ameh CA, Kerr R, Madaj B, et al. Knowledge and skills of healthcare providers in sub-Saharan Africa and Asia before and after competency-based training in emergency obstetric and early newborn care. Plos One 2016;11:e0167270.

20 Harvey SA, Ayabaca P, Bucagu M, et al. Skilled birth attendant competence: an initial assessment in four countries, and implications for the safe motherhood movement. Int J Gynecol Obstet 2004;87:203-10.

21 Harvey SA, Blandón YCW, McCaw-Binns A, et al. Are skilled birth attendants really skilled? A measurement method, some disturbing results and a potential way forward. Bull World Health Organ 2007;85:783-90.

22 Murray SF, Pearson SC. Maternity referral systems in developing countries: current knowledge and future research needs. Soc Sci Med 2006;62:2205-15.

23 Austin A, Gulema H, Belizan M, et al. Barriers to providing quality emergency obstetric care in Addis Ababa, Ethiopia: healthcare providers' perspectives on training, referrals and supervision, a mixed methods study. BMC Pregnancy Childbirth 2015;15:74.

24 Knight HE, Self A, Kennedy SH. Why are women dying when they reach hospital on time? A systematic review of the 'third delay'. PLoS One 2013;8:e63846.

25 Cavallaro FL, Marchant TJ. Responsiveness of emergency obstetric care systems in low- and middle-income countries: a critical review of the "third delay". Acta Obstet Gynecol Scand 2013;92:496-507.

26 Ebener S, Stenberg K, Brun M, et al. Proposing standardised geographical indicators of physical access to emergency obstetric and newborn care in low-income and middle-income countries. BMJ Global Health 2019;4:e000778.

27 Heyen-Perschon J. Report on current situation in the health sector of Senegal and possible roles for non-motorised transport interventions. institution for transportation and development policy, 2005. Available: https://www.itdp.org/wp-content/uploads/2014/07/ ITDP-Transport-and-Health-Care-Senegal.pdf [Accessed Feb 2019].

28 Golding N, Burstein R, Longbottom J, et al. Mapping under-5 and neonatal mortality in Africa, 2000-15: a baseline analysis for the sustainable development goals. Lancet 2017;390:2171-82.

29 ANSD [Sénégal] and ICF. Sénégal: Enquête Démographique et de Santé Continue (EDS-Continue 2017). Rockville, Maryland, USA: ANSD and ICF, 2018. Available: https://www.dhsprogram.com/pubs/ pdf/FR345/FR345.pdf [Accessed Jan 2019].

30 Ministère de la Santé et de l'Action Sociale. Pyramide de Santé. Available: http://www.sante.gouv.sn/politique-de-sante/pyramidede-sante [Accessed Feb 2019].

31 Trends in maternal mortality 2000 to 2017 : estimates by who, UNICEF, UNFPA, world bank group and the United nations population division. Geneva: World Health organization, 2019. Available: https://www.who.int/reproductivehealth/publications/ maternal-mortality-2000-2017/en/ [Accessed Nov 2019].

32 Ministère de la Santé et de la Prévention du Sénégal. Plan national de Développement Sanitaire PNDS 2009-2018, 2009. Available: http://www.who.int/pmnch/media/events/2014/sen_pnds.pdf [Accessed Sep 2018].

33 Witter S, Dieng T, Mbengue D, et al. The National free delivery and caesarean policy in Senegal: evaluating process and outcomes. Health Policy Plan 2010;25:384-92.

34 Joseph G, da Silva ICM, Wehrmeister FC, et al. Inequalities in the coverage of place of delivery and skilled birth attendance: analyses of cross-sectional surveys in 80 low and middle-income countries. Reprod Health 2016;13:77.

35 UNFPA. State of the world's midwifery 2014: a universal pathway. A woman's right to health. New York: United nations population fund, 2014. Available: https://www.unfpa.org/sites/default/files/pub-pdf/ EN_SoWMy2014_complete.pdf [Accessed Sep 2018].

36 Wang W, Mallick L, Allen C, et al. Effective coverage of facility delivery in Bangladesh, Haiti, Malawi, Senegal and Tanzania. DHS analytical studies No. 65. Rockville, Maryland, USA: ICF, 2018.
Available: https://www.dhsprogram.com/pubs/pdf/AS65/AS65.pdf [Accessed Jan 2019].

37 The DHS Progam. DHS overview. Available: http://dhsprogram.com/ What-We-Do/Survey-Types/DHS.cfm [Accessed Nov 2019].

38 The DHS Progam. Continuous Demographic and Health Survey. USAID, President's Malaria Initiative, ANSD, Ministere de la Santé et I'Action Sociale, UNICEF \& UNFPA. Available: https://dhsprogram. com/pubs/pdf/DM34/DM34.pdf [Accessed Feb 2019].

39 The DHS Progam. Spa overview. Available: https://dhsprogram.com/ What-We-Do/Survey-Types/SPA.cfm [Accessed Sep 2019].

40 ANSD [Sénégal], ICF. Sénégal : Enquête Continue sur la Prestation des Services de Soins de Santé (ECPSS) 2017. Dakar, Sénégal and Rockville, Maryland, USA: ANSD and ICF, 2018. Available: https:// dhsprogram.com/pubs/pdf/SPA27/SPA27.pdf [Accessed Nov 2019].

41 Ministère de la Santé et de l'Action Sociale [Sénégal], USAID. National health facility census 2012

42 WorldPop. Senegal $100 \mathrm{~m}$ population. school of geography and environmental science, University of Southampton, 2015. Available: https://www.worldpop.org/geodata/summary?id=127 [Accessed Nov 2019].

43 Dumont A, Fournier P, Fraser W, et al. QUARITE (quality of care, risk management and technology in obstetrics): a cluster-randomized trial of a multifaceted intervention to improve emergency obstetric care in Senegal and Mali. Trials 2009;10:85.

44 Enquête de base aupres des points de prestation de services pour l'initiative sénégalaise de santé urbaine (issu) 2011 : Rapport principal: IntraHealth International 2012.

45 UNPD. World Population Prospects - Total Population - Both sexes, 2017. Available: https://esa.un.org/unpd/wpp/Download/Standard/ Population/ [Accessed Mar 2018].

46 UNPD. World Population Prospects - Crude Birth Rate, 2017. Available: https://esa.un.org/unpd/wpp/Download/Standard/Fertility/ [Accessed Mar 2018].

47 WHO, UNFPA, UNICEF. Monitoring emergency obstetric care: a Handbook. Geneva, Switzerland: World health organisation, 2009. Available: https://www.who.int/reproductivehealth/publications/ monitoring/9789241547734/en/ [Accessed Nov 2019].

48 R Core Team. R: a Inaguage and environment for statistical computing. Vienna, Austria: R foundation for statistical computing, 2019. Available: https://www.R-project.org/ [Accessed Jan 2020].

49 OSRM R package. Available: https://github.com/rCarto/osrm [Accessed Nov 2019].

50 Package 'osrm', 2019. Available: https://cran.r-project.org/web/ packages/osrm/osrm.pdf [Accessed Nov 2019].

51 OSRM profiles. Available: https://github.com/Project-OSRM/osrmbackend/blob/master/docs/profiles.md [Accessed Nov 2019].

$52 \mathrm{Ng} \mathrm{M}$, Fullman N, Dieleman JL, et al. Effective coverage: a metric for monitoring universal health coverage. PLoS Med 2014;11:e1001730 $-\mathrm{e} 30$.

53 Willey B, Waiswa P, Kajjo D, et al. Linking data sources for measurement of effective coverage in maternal and newborn health: what do we learn from individual- vs ecological-linking methods? $J$ Glob Health 2018;8:010601-01.

54 Do M, Micah A, Brondi L, et al. Linking household and facility data for better coverage measures in reproductive, maternal, newborn, and child health care: systematic review. J Glob Health 2016;6:020501

55 WHO. Who statement on caesarean section rates. World health organisation, 2015. Available: http://apps.who.int/iris/bitstream/ 10665/161442/1/WHO_RHR_15.02_eng.pdf?ua=1 [Accessed Nov 2019].

56 RCOG. Classification of urgency of caesarean section - a continuum of risk. Royal College of Obstetricians and Gynaecologists, Royal College of Anaesthetists, 2010. Available: https://www.rcog.org.uk/ globalassets/documents/guidelines/goodpractice11classificationofur gency.pdf [Accessed Nov 2019].

57 ACOG, The College. Standards for obstetric services. 6th edn. Washington, DC, 1988.

58 Say L, Chou D, Gemmill A, et al. Global causes of maternal death: a who systematic analysis. Lancet Glob Health 2014;2:e323-33.

59 Pattinson RC, Makin JD, Pillay Y, et al. Basic and comprehensive emergency obstetric and neonatal care in 12 South African health districts. S Afr Med J 2015;105:2015.

60 Windsma M, Vermeiden T, Braat F, et al. Emergency obstetric care provision in southern Ethiopia: a facility-based survey. BMJ Open 2017;7:e018459.

61 Ministère de la Santé et de l'Action Sociale [Senegal]. Document Cadre de la Stratégie des Sages-Femmes Itinérantes. Available: http://www.sante.gouv.sn/sites/default/files/sfstragitinerante.pdf [Accessed Jun 2019]. 
62 Setal.net. Awa Marie Coll Seck "Il est prévu, bientôt, le recrutement de près de 200 sages-femmes", 2017. Available: https://www.setal. net/AWA-MARIE-COLL-SECK-II-est-prevu-bientot-le-recrutementde-pres-de-200-sages-femmes a53315.html [Accessed Sep 2018].

63 Hanson C, Gabrysch S, Mbaruku G, et al. Access to maternal health services: geographical inequalities, United Republic of Tanzania. Bull World Health Organ 2017;95:810-20.

64 Radovich E, Benova L, Penn-Kekana L, et al. 'Who assisted with the delivery of (NAME)?' Issues in estimating skilled birth attendant coverage through population-based surveys and implications for improving global tracking. BMJ Global Health 2019;4:e001367.

65 Stanton CK, Rawlins B, Drake M, et al. Measuring coverage in $\mathrm{MNCH}$ : testing the validity of women's self-report of key maternal and newborn health interventions during the peripartum period in Mozambique. PLoS One 2013;8:e60694.

66 Hanson C, Schellenberg J. Redesigning maternal health services: is centralisation the answer in low-resource settings? BMJ Global Health 2019;4:e001488.

67 Gao Y, Zhou H, Singh NS, et al. Progress and challenges in maternal health in Western China: a countdown to 2015 national case study. Lancet Glob Health 2017;5:e523-36.

68 Hussein J, Kanguru L, Astin M, et al. The effectiveness of emergency obstetric referral interventions in developing country settings: a systematic review. PLoS Med 2012;9:e1001264.

69 Ngoma T, Asiimwe AR, Mukasa J, et al. Addressing the second delay in saving mothers, giving life districts in Uganda and Zambia: reaching appropriate maternal care in a timely manner. Glob Health Sci Pract 2019;7:S68-84.

70 Rawlins B, Plotkin M, Rakotovao JP, et al. Screening and management of pre-eclampsia and eclampsia in antenatal and labor and delivery services: findings from cross-sectional observation studies in six sub-Saharan African countries. BMC Pregnancy Childbirth 2018;18:346.

71 Hanson C, Munjanja S, Binagwaho A, et al. National policies and care provision in pregnancy and childbirth for twins in eastern and southern Africa: a mixed-methods multi-country study. PLoS Med 2019;16:e1002749.

72 Virgo S, Gon G, Cavallaro FL, et al. Who delivers where? the effect of obstetric risk on facility delivery in East Africa. Trop Med Int Health 2017;22:1081-98.

73 Cavallaro FL, Benova L, Macleod D, et al. Examining trends in family planning among harder-to-reach women in Senegal 1992-2014. Sci Rep 2017;7:41006.

74 Suh S. What post-abortion care indicators don't measure: Global abortion politics and obstetric practice in Senegal. Soc Sci Med 2019:112248.

75 Larson E, Vail D, Mbaruku GM, et al. Beyond utilization: measuring effective coverage of obstetric care along the quality cascade. Int $J$ Qual Health Care 2017;29:104-10.

76 ANSD [Sénégal]. Situation Economique et Sociale Du Sénégal en 2016. Dakar, Senegal: ANSD, 2019. Available: http://www.ansd.sn/ ressources/ses/SES_2016_fin.pdf [Accessed Aug 2019].

77 WorldPop. Senegal $1 \mathrm{~km}$ pregnancies. school of geography and environmental science, University of Southampton, 2015. Available: https://www.worldpop.org/geodata/summary?id=1021 [Accessed Sep 2019].

78 ANSD [Sénégal] and ICF International. Senegal continuous service provision assessment 2017 dataset, 2017. Available: https:// dhsprogram.com/what-we-do/survey/survey-display-535.cfm [Accessed Nov 2019]. 